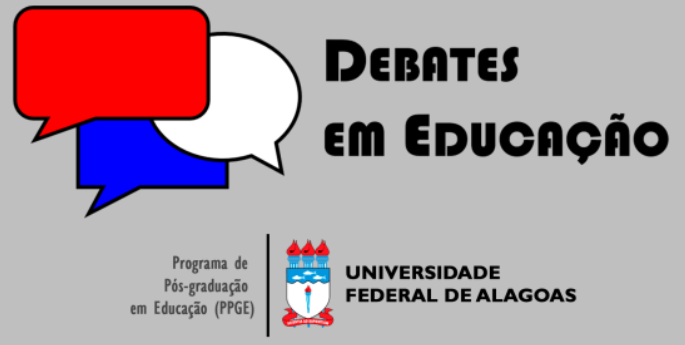

ISSN Eletrônico 2175-6600

Vol. II | No. 25 | Set./Dez. | 2019

Francisco Thiago Silva

9 iD

Universidade de Brasília (UnB)

francisco.thiago@unb.br

Lívia Freitas Fonseca Borges

9 iD

Universidade de Brasília (UnB)

liviaffb@unb.br

\section{O CENÁRIO DA FORMAÇÃO DE PROFESSORES NO BRASIL NOS VINTE ANOS DA ATUAL LDB}

\section{RESUMO}

Passados vinte anos da promulgação da nossa LDB 9394/96, tecemos algumas considerações em torno das questões atinentes à formação de professores no Brasil, buscando destacar avanços e recuos nas políticas públicas educacionais nas licenciaturas. Por meio de análise documental e levantamento bibliográfico, concluímos que esse é um campo de investigação bastante explorado, mas ainda detentor de questões candentes, a exemplo da avalanche conservadora que tomou conta do país nos últimos três anos para prover reformas na Educação Básica. A política de formação de professores no Brasil conta com excesso de instrumentos normativos e carência de recursos financeiros e materiais.

Palavras-chave: Formação de professores no Brasil. Vinte anos de LDB.

\section{THE SCENARIO OF TEACHER EDUCATION IN BRAZIL IN THE TWENTY YEARS OF THE CURRENT LDB}

\section{ABSTRACT}

Twenty years after the promulgation of our LDB 9394/96, we made some considerations around the issues related to teacher education in Brazil, seeking to highlight advances and setbacks in educational public policies in undergraduate degrees. Through documentary analysis and bibliographical survey, we conclude that this is a field of research well explored, but still with burning questions, such as the conservative avalanche that has taken over the country over the past three years to provide reforms in basic education. Teacher education policy in Brazil has an excess of regulatory instruments and lack of financial and material resources.

Keywords: Teacher education in Brazil. Twenty years of LDB.

Submetido em: 01/03/2019

Aceito em: 03/1 1/2019

Publicado em: 23/I2/2019

doi) http://dx.doi.org//0.28998/2175-6600.2019v| In25p I39-I 54 


\section{A LDB VINTE ANOS DEPOIS}

O cenário político e econômico do país vinte anos depois da promulgação da atual Lei de Diretrizes e Bases da Educação Nacional, Lei n 9394/96, infelizmente não é muito alvissareiro. Imersos em uma crise política, presenciamos os equívocos do parlamento na destituição da primeira mulher legitimamente eleita para a presidência da república e uma avalanche conservadora tomando conta da política educacional (FRIGOTTO, 2016).

Uma profusão de instrumentos normativos se sobrepõe em um cenário de disputas ideológicas em que a produção acadêmica de perspectiva crítica é olvidada pelos fazedores de leis e por agentes públicos e sociais que não se apropriam devidamente dos registros da nossa história política e educacional. Essa perspectiva nos remete ao entendimento de que o materialismo histórico dialético ainda representa um campo teórico profícuo para sustentar as temáticas educacionais da atualidade e nesta mesma perspectiva não encontramos sustentação nos argumentos teóricos de cariz pós-modernos.

O movimento reformista e reacionário que tomou conta dos debates no campo educacional é alimentado principalmente pelo relativismo das concepções pós-modernas de sociedade e do ensino ligadas ao campo curricular, que em geral se traduzem nas seguintes ideias:

[...] as pedagogias hegemônicas, como o construtivismo, a pedagogia das competências, a pedagogia dos projetos, a teoria do professor reflexivo e o multiculturalismo pertencem a um universo ideológico constituído tanto pelo neoliberalismo quanto pelo pós-modernismo [...] o relativismo trazido da ideologia pós-moderna para o campo educacional soma-se ao pragmatismo neoliberal, marcando de modo comprometedor a função social da escola, que, mais que nunca, mostra-se aprisionada nos limites da vida cotidiana, assumida como instância da prática social (MALANCHEN, 2016, p. 8).

Além disso, tem-se como pano de fundo a retomada institucional do neotecnicismo (FREITAS, 20 I I), regado por pacotes educacionais incorporados pelos sistemas públicos de ensino e a promoção de formação continuada de professores, em sua maioria realizada na modalidade à distância, sem a qualidade necessária. Todo esse processo é orientado pelo pragmatismo neoliberal que insiste em tomar a iniciativa privada como modelo avaliativo para o setor público (SAVIANI, 20I5), o que atinge por um flanco a formação de professores no país, notadamente após a LDB.

A universitarização docente, isto é, a formação do professor em nível superior que decorre da exigência legal, é apropriadamente definida por Carneiro.

O professor formado em nível universitário tende a ser capaz de estabelecer uma nova relação com o conhecimento acumulado, assumindo a postura de (des)construtor de saberes, em um processo mediado pelas relações sócio- pedagógicas que estabelece com os alunos e com os profissionais da escola. Assim concebido, o professor é muito mais do que um "dispensador de saberes", pois se coloca como produtor de conhecimento pedagógico, como pesquisador, enfim, como intelectual. (CARNEIRO et. al., 20 I0, p. 3) 
A grande meta da universitarização da formação docente tão conclamada pela referida lei ainda concorre com a formação de professores na educação básica, equivocadamente retomada no Documento Final da Conferência Nacional de Educação (de 2014, no Eixo II, em Proposições e Estratégias, nos itens 19 e 87) ao tratar do ensino médio, na modalidade normal. Desse modo, ainda subsiste uma defesa do curso normal para prover a formação de professores, que, no nosso entendimento, já deveria estar superada pela formação na educação superior. Nisto reside um significativo recuo das políticas públicas educacionais pós LDB.

Embora reconheçamos a necessidade da formação superior do professor da educação básica, convivemos com a defesa dos saudosistas das escolas normais a pretexto da desqualificação dos cursos de pedagogia. Esse é um dilema que precisamos resolver. Não é defendendo o retorno da qualidade atribuída ao que se fazia antes da LDB que vamos melhorar a qualidade dos cursos de formação de professores no país.

A temática também é objeto de análise e pronunciamento de Libâneo e Pimenta (20II) ao criticarem a hegemonia de modelos únicos nas propostas de formação de professores no Brasil. Ao mesmo tempo os referidos autores reconhecem as limitações a serem superadas pelo curso normal de nível médio e a impropriedade do que se tentou impor nas reformas da educação superior no final dos anos 1990 com o suspeito e mal acabado Curso Normal Superior que as experiências o levaram à inanição.

Outro recuo está assentado nos precedentes das novas diretrizes de 2015, quando permitem aproveitamento da experiência docente para reduzir a carga horária de estágio. Isso na verdade não é novo; já estava presente na Resolução 2/2002. A carga horária da segunda licenciatura ainda é incipiente diante das demandas reais de um processo formativo pleno que seja capaz de provocar mudanças teóricas e práticas na formação do professor que já se encontra em exercício da docência.

Na mesma direção, avaliamos os limites da formação pedagógica dos não licenciados, onde se situam os bacharéis de forma geral e os tecnólogos. As DCN não apresentam parâmetros de exigências mínimas de referência para os projetos pedagógicos dos respectivos cursos que se desdobrarão dessas demandas, o que faculta às instituições formadoras um largo campo de autonomia.

Um avanço foi ter colocado como exigência que a primeira licenciatura deva cumprir um mínimo de quatro anos e elevar a carga horária de todos os cursos de 2.800 para 3.200h, provavelmente tendo como parâmetro as DNC da Pedagogia.

A profissão docente no Brasil passa por uma situação curiosa em relação às pessoas que, embora não tenham a formação necessária para o exercício da docência, almejam de forma tangencial o direito de lecionar. Essa situação, ao invés de contribuir para a valorização do campo profissional, não a transforma em um campo social de conhecimentos valorizados, mas demonstra que este é um território em que 
todos podem adentrar com ou sem formação, distorção inclusive fomentada por iniciativas equivocadas a partir da política pública educacional.

A pretexto da açodada urgência da reforma do Ensino Médio no Brasil, tomamos como exemplo desse fato a recente publicação da Medida Provisória 746/20 I 6 que tramita no Congresso Nacional como proposta de modificação da LDB, que entre as impropriedades apresenta a possibilidade do "notório saber" para atuar em sala de aula. Art. 6 I [...] - IV - profissionais com notório saber reconhecido pelos respectivos sistemas de ensino para ministrar conteúdos de áreas afins à sua formação para atender o disposto no inciso $V$ do caput do art. 36. (BRASIL, 2016).

Para corrigir essa distorção, entre outras, que levam à desprofissionalização da docência - termo aqui apropriado a partir das referências desenvolvidas por Nóvoa (1999), é que existe uma lei de diretrizes e bases da educação nacional. Para regular e servir de parâmetro da legalidade e organização da educação e de tudo mais que dela decorre.

\section{QUAL É O PROBlema dA AusÊnCIA OU EXCESSO DE REGULAÇÃO EDUCACIONAL?}

Valendo-nos da "teoria da curvatura da vara" em Saviani (20I2), encontramos o caminho do equilíbrio entre os pêndulos que ao mesmo tempo reconhecem a necessidade de uma legislação nacional que repercute nas outras esferas dos sistemas de ensino, bem como os efeitos nefastos dos excessos. Aliás, o que mais se tem vivido nos últimos anos em nosso país é uma sobrecarga de instrumentos normativos que orientam a política nacional de educação, em particular no campo da formação de professores.

Por que a educação necessita de uma lei de diretrizes e bases em dimensão nacional? Porque do contrário, viveríamos sem referências e garantias do estado democrático de direito e das relações institucionais e pessoais. Correríamos o risco de sermos pautados pelo improviso e pela superficialidade.

Ao analisar os efeitos da relação entre educação e modo de produção capitalista, Saviani situa as transformações na regulação das relações sociais e na constituição da própria sociedade.

[...] Na sociedade moderna, capitalista, as relações deixam de ser naturais para serem dominantemente sociais, neste sentido é que a sociedade capitalista rompe com a ideia de comunidade, pra trazer, com toda a força, a ideia de sociedade. Sendo assim a sociedade capitalista traz a marca de um rompimento com a estratificação de classes. Isto é posto em evidência pelo fato de que a sociedade deixa de se organizar segundo o direito natural, mas passa a se organizar segundo do direito positivo, um direito estabelecido formalmente por convenção contratual. É por isso que os ideólogos da sociedade moderna vão fazer referência ao chamado contrato social e à sociedade como sendo reorganizada através de um contrato e não por laços naturais. (SAVIANI, 1994, p. I55) 
A partir desse entendimento de sociedade, cuja complexidade deriva das relações de produção, situa-se a necessidade de regulação das políticas educativas representadas por força de uma lei nacional que oriente toda e qualquer matéria concernente à educação. Uma lei geral é evocada para dar materialidade a esse ideário.

No contexto de 1996, a LDB emerge de uma estrutura política republicana, calcada nos princípios de uma jovem democracia presidencialista. Derivada de nossa sétima constituição federal, denominada "Constituição cidadã", a nossa lei maior da educação surgiu com o intento de promover educação de qualidade, com amplo acesso e calcada nos ideais de uma sociedade próspera e mais justa. (SAVIANI, 2004)

Os efeitos dos princípios que orientaram a Revolução Francesa, que na verdade se reconfigurou como o golpe da burguesia ascendente, que passa de revolucionária a conservadora (HOBSBAWN, 1996) parecem ecoar no cenário educativo brasileiro. Se vivenciássemos a experiência de uma sociedade sem lei, regulada pela anarquia, defenderíamos o privilégio do poder do mais forte. O domínio de uma pequena parcela da sociedade detentora dos meios de produção encontra espaço no contexto da crítica ao capitalismo desenvolvida pela obra referencial de Marx.

De forma surpreendente, somos demandados por profissionais cuja formação e área de atuação não os autorizariam a ministrar aulas ou conferir certificação de cursos livres ou até mesmo de especialização. Esse fato se sustenta na crença de que a educação é "terra de ninguém", acreditando na existência dos incautos e da impunidade ao arrepio da lei. Ações inapropriadas de sujeitos que ousam praticar atividades de ensino a pretexto da vanguarda, da inovação que se antecipa ao estado regulador. Não é simplesmente colocar uma banca na feira e vender um produto, eis a metáfora da distorção entre a formação e a atuação profissional.

Reina o entendimento equivocado de que o mero exercício da atividade de ensino é suficiente para autorizar e legitimar formações clandestinas, o que ao mesmo tempo contribui com a desqualificação e a desprofissionalização docente. Não somos contrários ao ingresso na carreira docente de profissionais oriundos de diversos campos do conhecimento, conquanto que sejam inseridos em itinerários formativos institucionais da docência, com ênfase no processo pedagógico.

Situação similar é criticada por Malanchen (2016, p. 8) ao afirmar que desde as reformas legislativas na educação brasileira, especialmente nos textos legais que tratam da formação de professores que desembocam na educação básica, existe uma "[...] desvalorização do conhecimento objetivo e o esfacelamento do currículo", uma vez que:

[...] o relativismo trazido da ideologia pós-moderna para o campo educacional soma-se ao pragmatismo neoliberal, marcando de modo comprometedor a função social da escola, que, mais que nunca, mostra-se aprisionada nos limites da vida cotidiana, assumida como instância única da prática social (IDEM). 
Brasil imerso no contexto da sociedade ocidental estruturada nos cânones do direito positivo, tradição germinada na herança cultural greco-romana, traduz para a educação a necessidade premente de estribar os princípios educacionais nas bases da legalidade para evocar legitimidade e até mesmo coesão social (MELLO, 2000).

Entre os avanços nesse período histórico da legislação educacional destacamos a Lei 10.639/03 na formação de professores e o pertencimento étnico, que alterou o artigo 26 da LDB. A esse respeito podemos situar o trabalho de Silva.

O efeito legal resultante foi uma política nacional de implementação da lei por meio da produção de materiais didáticos e de pesquisa, além da entrada da disciplina História e cultura africana e afrobrasileira nos cursos de graduação, principalmente no de história. (SILVA, 20I5, p. 26)

O Plano Nacional de Educação - PNE, instituído pela Lei n 13.005, de 25 de Junho de 2014, contraditoriamente, serve de referência para avanços e recuos no período pós LDB, na compreensão de que especializamo-nos em estabelecer metas inatingíveis ${ }^{1}$. Vale também destacar que segundo Davies (20 I0), o PNE foi introduzido no texto da Constituição Federal nos primórdios da Nova República e nos dias atuais nos serve de apanágio de uma categoria profissional historicamente excluída da centralidade da pauta política nacional.

\section{$3 \quad$ POR QUE NOS TORNAMOS PROFESSORES?}

Na difícil escolha imposta aos estudantes do ensino médio ou adultos desempregados em busca de uma recolocação no mercado de trabalho, surge a opção profissional pelo magistério. Frases como "essa é uma profissão ingrata"; "você tem condições de fazer escolhas melhores" entre outras de igual teor, construídas no imaginário social em larga medida têm contribuído para o desprestígio da carreira. Em um contexto adverso, capturamos no trabalho referencial de Adorno (2006), em que denomina apropriadamente os "Tabus acerca do magistério", considerações textuais que em larga medida se assemelham ao cenário histórico em que a profissão foi implantada no Brasil e que demoveram tantos das decisões de seguirem na seara das licenciaturas ou que nela se mantiveram apesar do desinteresse, o que na realidade é um fenômeno danoso, do ponto de vista do sofrimento pessoal e da baixa qualidade do que se produz no contexto laboral.

Entre as ponderações de Adorno (ldem), encontramos ainda uma semelhança na desvalorização que atribuímos aos professores da educação infantil e dos anos iniciais do ensino fundamental em relação aos professores que atuam na educação superior. Esse pode ser identificado como outro limite do texto

\footnotetext{
' Meta 16 - Formação continuada e pós-graduação de professores Formar, em nível de pós-graduação, 50\% dos professores da educação básica, até o último ano de vigência deste PNE, e garantir a todos os(as) profissionais da educação básica formação continuada em sua área de atuação, considerando as necessidades, demandas e contextualizações dos sistemas de ensino.
} 
legal, que embora tenha aglutinado todos os níveis, etapas e modalidades da educação nacional, não conseguiu romper.

Nessa direção, encontramos esse fenômeno social de desvalorização da profissão e fuga dos egressos das licenciaturas no Brasil nas pesquisas de Gatti (2009), ao denominar a escolha como uma espécie de "seguro desemprego" e ressaltar que ainda é pífio o quantitativo de profissionais formados pelas universidades, atuando profissionalmente nas escolas dos sistemas público de ensino ou que nele pretendam atuar.

Os estudos realizados por Ferretti contribuem para qualificar o debate das escolhas profissionais ao apontar os equívocos das opções calcadas no arbítrio individual:

[...] Tal enfoque desconsidera o dinamismo da vida social e do próprio fenômeno da decisão profissional, as inter-relações entre as forças políticas, econômicas e sociais que atuam num dado momento, assim como o dado óbvio de que o ingresso em um determinado setor e ocupação do mercado de trabalho não é fruto apenas da decisão pessoal. (FERRETTI, 1997, pp. 57-58)

Para além do "otimismo pedagógico" vivido em nosso país, mais notadamente nos anos iniciais do século XX (ROCHA, 2000), cujo ideário posicionava as questões pedagógicas no centro da qualidade da educação e, por consequência do ensino, é preciso considerar que essa pretensa qualidade implica fatores diversos entre os quais figuram supletivamente a formação dos professores.

[...] o entusiasmo pela educação e o otimismo pedagógico, que tão bem caracterizaram a década dos anos vinte, começam por ser, no decênio anterior, uma atitude que se desenvolveu nas correntes de ideias e movimentos político-sociais e que consistia em atribuir importância cada vez maior ao tema da instrução, nos seus diversos níveis e tipos. É essa inclusão sistemática dos assuntos educacionais nos programas de diferentes organizações que dará origem àquilo que, na década dos vinte, está sendo denominado entusiasmo pela educação e otimismo pedagógico. (NAGLE, 200।, pp. 135-136).

Sem sombras de dúvidas as influências que o indivíduo recebe em seu ambiente social a respeito da profissão docente, tanto podem ser positivas quanto negativas, dependendo de como o sujeito espelhado se comporta diante das atividades laborais e das suas condições intelectuais e materiais de subsistência. Nesse contexto adverso da profissão docente no Brasil, é preciso encontrar um prumo positivo dessa referência para promover o engajamento de jovens e maduros talentos para o magistério, sem romantismo, mas buscando a necessária provisão das reais necessidades dos indivíduos e das instituições formadoras para atuarem com plenitude.

Evidentemente que não podemos desconsiderar as condições materiais da profissão. Ainda temos muito que lutar pela carreira e condições de trabalho, entretanto essa ainda é uma considerável oferta de postos de trabalho, o que não pode ser a razão principal para que os trabalhadores tenham inserção e permanência na carreira docente.

Libâneo identifica a ausência de propostas de intervenção em nível federal para romper com as atuais fragilidades dos projetos de formação docente, emanadas da LDB, que em muitos casos são 
orientadas por contraditórias políticas de organismos internacionais. Para o autor, as iniciativas nesse sentido,

[...] têm sido, ainda, bastante modestas, porque não tratam a questão no seu conjunto. A vinculação da política educacional nacional às diretrizes do Banco Mundial (que induz as reformas educativas nos países periféricos) tem provocado situações ambivalentes. Por um lado, acentuase a necessidade de uma nova qualidade educativa implicando a necessidade de mudanças nos currículos, na gestão educacional, na avaliação dos sistemas e, em especial, na profissionalização dos professores. Por outro, impõem-se medidas restritivas a investimentos públicos (inclusive pagamento de salários e financiamento da formação). (LIBÂNEO, 20I0, p. 9I).

Curiosa e injustificável torna-se uma política nacional sustentada na falsa possibilidade de homogeneidade formativa. $\bigcirc$ Brasil precisa se conhecer por dentro antes de buscar referenciais externos para pautar sua agenda educacional, seja pela necessidade de busca de recursos financeiros nos organismos internacionais, seja pela falsa ideia de uma incompetência nossa de apresentar saídas plausíveis para os problemas que nos são próprios. Isso não significa levantar uma bandeira endógena, o que seria no mínimo expressão de ingenuidade; ao contrário conhecer o contexto internacional para não repetir seus erros.

Merece reflexão a retomada do estudo de Gatti e de sua atualização em 2019 em que retrata um panorama dos egressos das licenciaturas em nosso país, relevando que, grande parte dos nossos docentes provém das instituições privadas de ensino, e que ainda é pouco expressiva a quantidade de professores da educação básica formados nas universidades públicas, razão pela qual não podemos simplesmente desqualificar essa formação, mas ao mesmo tempo precisamos lutar pela ampliação de vagas em universidades públicas, bem como contribuir para a formação continuada em serviço dos profissionais egressos desses cursos superiores, professores que dão sustentação à oferta do ensino nas escolas públicas de todo o país.

A expansão das matrículas acontece, sobretudo, por meio da via privada. Se em meados da primeira década, no cômputo geral das licenciaturas, o número de matrículas no setor privado já era maior do que no público (54\% e 45\%), essa diferença se acentua muito até 2016: as instituições privadas passam a responder por $62 \%$ dos estudantes, enquanto as públicas se responsabilizam por 38\% deles (GATTI, 2009, p. I 13).

No afã de garantir a presença de professores nas escolas, como se isso fosse o critério mais importante para garantir uma educação de excelência, vimos, na última década, políticas públicas sendo fomentadas na perspectiva empresarial e privativista (MACEDO, 20।4), sob o pretexto dos estudos de impacto ou mesmo os possíveis precedentes da própria LDB atual. Num movimento inverso que não pode ser visto de forma estática, Saviani (2015) aponta como a iniciativa privada tem avaliado o público, quando na verdade deveria ser o contrário. Nesse sentido se manifestam Machado e Paixão (20 I 5, p. I 30):

As mudanças ocorridas no ensino superior brasileiro privilegiaram a iniciativa privada e uma maior atuação mercadológica no setor educacional. Ficou claro na LDB n 9.394/96 (BRASIL, 1996) que o mercado é um bom empreendedor e que a privatização deve ser adotada. Esse ideal colaborou para a criação de um mercado educacional. (MACHADO e PAIXÃO, 20 I 5, p. I30). 
A herança da Paidéia (CAMBI, 1999) deve persistir no DNA da profissão que reflete a sua configuração nos dias atuais, atribuindo ao campo o reconhecimento do seu valor científico. Dos sofistas que ofereciam gratuitamente seu trabalho intelectual à experiência da escravização da mão de obra humana nas origens do Brasil, desenvolvemos as bases que influenciaram a organização do trabalho em nosso país. Essa situação é explicada por Santos (2003, p. 205): "Assim sendo, a gênese do preconceito contra o trabalho manual vai estar centrada muito mais no tipo de inserção do trabalhador na sociedade (se escravo ou homem livre), e muito menos na natureza da atividade em si". Ou seja, ao trabalho de menor valor intelectual é atribuído o baixo status social da profissão, cuja gênese é situada na sociedade clássica como trabalho servil. É preciso desconstruir a ideia de magistério como trabalho voluntário, sem prestígio e mal pago. É preciso consolidar os caminhos da profissionalização docente (NÓVOA, I999; IMBERNÓN, 2005).

Da herança histórica do Brasil colônia até o momento atual, a formação docente não sofre ausência de identidade, mas de alçar o lugar que the é reservado nas políticas educacionais, sustentadas pelos recursos que lhe são devidos. Isso a LDB ainda não deu conta de garantir, o que faz supor que padecemos de ações políticas efetivas mais que instrumentos legais e normativos para orientar os processos formativos dos docentes no país.

\section{BREVE REVISÃO SOBRE A LDB E A FORMAÇÃO DE PROFESSORES}

Conhecer o que outros pesquisadores têm dito a respeito da nossa temática central aqui proposta torna-se tarefa indispensável para apontar avanços e recuos nesse percurso educacional. Dados os limites deste texto, provavelmente muitos autores não figurarão nas discussões; apenas nos reportamos aos que mais se aproximavam do nosso recorte reflexivo. Para além da análise de fragmentos de textos legais, as lacunas teóricas são apontadas com frequência pelos nossos especialistas educacionais, a exemplo do trabalho de Silva (2007), ao denunciar uma verdadeira deserção com relação às construções teóricas produzidas no pensamento social brasileiro.

Isso precisa ser levado em consideração tanto para a educação em sentido amplo, como para o campo curricular em sentido estrito, com ênfase no cenário teórico educacional contemporâneo ainda tão fragmentado que precisa revelar seu potencial político de forçar as mudanças sociais, políticas e culturais desejadas em favor dos sujeitos e das instituições formadoras de professores.

Mais uma vez reiteramos que a força do instrumento normativo para impingir a pauta dos atores que se revezam no poder político não pode suprimir a necessária construção epistemológica que antecede e explica os fatos, antes e depois de ocorridos. Tal situação será possível desde que nos lembremos das advertências pertinentes de Silva. 
Foge-se da teoria em favor de uma prática supostamente mais urgente. Foge-se da teoria em favor de uma militância política supostamente mais valorizada. Marginaliza-se o pensamento teórico para buscar refúgio numa envergonhada prática paternalista e assistencialista disfarçada de intervenção política. Deixa-se de lado a teorização política para buscar abrigo num movimento moralista destituído de qualquer tentativa de compreensão mais lúcida das causas estruturais da miséria. (SILVA, 2007, p. 8).

Em outras palavras, Saviani contribui para esse debate, trazendo os conceitos de "verbalismo" e de "ativismo pedagógico", para decantar o imbróglio conceitual atinente aos discursos subsumidos na ausência de formação profissional docente, conforme apregoado pelo texto legal em pauta.

Percebemos, então, que o que se opõe de modo excludente à teoria não é a prática, mas o ativismo, do mesmo modo que o que se opõe de modo excludente à prática é verbalismo e não a teoria. Pois o ativismo é a "prática" sem teoria e o verbalismo é a "teoria" sem a prática. Isto é: o verbalismo é falar por falar, ou blá-blá-blá, o culto da palavra oca; e o ativismo é a ação pela ação, a prática cega, o agir sem rumo claro, a prática sem objetivo. (SAVIANI, 2012, pp. I09| 10)

Precisava ser um filósofo e historiador da educação para escrever com tanta propriedade uma súmula conceitual do que mais nos faz patinar no campo epistemológico da educação que nos é tão caro e ao mesmo tempo difícil de decifrar, ora recitado com propriedade, ora anunciado com superficialidade pelos profissionais que, embora se ocupem da educação, não a consideram ciência, razão pela qual buscam construir argumentos para a desprofissionalização do profissional e da profissão que consideram desprovidos de objeto epistêmico na sua essência. Nisso reside grande parte da justificativa para a profusão legislativa que mais nos confunde do que nos orienta.

Em obras referenciais dessa matéria, Saviani (2004) e Brzezinski (2008) discorrem sobre os desdobramentos normativos que o texto legal trouxe para a educação brasileira. Saviani (2004) considera que a ampliação do conceito de educação impresso na lei pode representar um ponto positivo, pois força o Estado a expandir a oferta educacional obrigatória e atender os que mais precisam da escola pública. Uma questão nevrálgica a considerar é que os gestores da política educacional, por força da própria LDB, se veem obrigados a apoiar movimentos minoritários da sociedade civil.

Não se pode perder de vista a análise materialista histórica dialética do filósofo paulista que chama a atenção para o fato de que vários dispositivos legais da educação foram aprovados antes da regulamentação da própria LDB, o que revela o caráter neoliberal e capitalista sob o qual a referida lei foi fundamentada.

Sobre a formação de professores Brzezinski (2008) reconhece avanços na LDB como a necessidade de um piso nacional para a carreira do magistério e a procura por desenhar uma identidade para a profissão docente no Brasil. Entretanto, a autora esclarece o caráter mercadológico e privatista do texto legal e destaca o problemático Art. 64 que abre uma contenda acerca da formação inicial mínima exigida para o magistério. O dispositivo determina que a Educação Superior seja o critério central para a atuação profissional de educadores, mas aceita o curso de magistério realizado em nível médio, curso 
normal, para credenciar docentes da educação infantil e dos anos iniciais do ensino fundamental. Além disso, o referido artigo mantém as antigas habilitações criadas na reforma do ensino do final dos anos 1960 (SAVIANI, 20 I2) e reforçadas na Resolução n I/2006 que instituiu as Diretrizes Curriculares Nacionais do Curso de Pedagogia. Mais uma profusão normativa que não dá conta de resolver as querelas entre licenciatura e bacharelado, docente e especialista. (LIBÂNEO, 2006)

Segundo Brzezinski (Idem), isso provoca um incentivo para o fomento de concursos públicos amparados no referido artigo da lei, resultando na precarização pedagógica e salarial desses profissionais empossados. A maioria, com formação superior, quiçá especialização, mas que pela necessidade empregatícia submete-se a um vencimento bem abaixo de sua formação, mas dentro da lei, ou seja, o curso normal sobrevive à custa do barateamento das contratações. Mais uma marca do retrocesso da nossa LDB.

Em outra perspectiva, encontramos em Melo (1999) uma saída para o impasse entre o que a LDB determina sobre como devam funcionar os programas oficiais de formação e a realidade onde esses profissionais irão atuar. Para a referida autora (1999, p, 45) o grande desafio é: "[...] construir o perfil e a identidade do profissional da educação, considerando os atores que atuam na escola e têm vínculo com o trabalho educativo: professores e funcionários da educação, portadores do direito a uma formação includente e de qualidade social". Poderíamos concordar com a autora se os óbices a tal intento residissem tão somente nos requisitos legais da formação dos professores, bem como nessa velha cantilena de que o maior problema da formação de professores no Brasil é a falta de identidade profissional, o que na verdade foi uma construção teórica e metodológica que não favoreceu a qualificação do campo.

Alguns avanços atribuídos à LDB na esfera jurídico-legal são apontados por Pereira (20 l 6), em que pese o fato de o estudioso reconhecer que até o presente momento não houve um grande projeto pedagógico nacional voltado para a formação e para a profissionalização de professores no Brasil. Segundo o referido autor:

No entanto, a urgência em qualificar um grande número de educadores para uma população escolar crescente sem o correspondente investimento financeiro por parte do governo leva à repetição de erros cometidos em um passado próximo e, consequentemente, revivem-se cenários de improvisação, aligeiramento e desregulamentação na formação de professores para o país. (PEREIRA, 2016, p. 139).

Carvalho esmiúça ponto a ponto o impacto da LDB na formação de professores para a educação básica e afirma que os seguintes itens tiveram alterações consideráveis:

[...] as finalidades e fundamentos da formação dos profissionais da educação; os níveis e o locus da formação docente e de "especialistas"; os cursos que poderão ser mantidos pelos Institutos Superiores de Educação; a carga horária da prática de ensino; a valorização do magistério e a experiência docente (CARVALHA, 1998, p. 2). 
Do conjunto da obra da pesquisadora, depreendemos que de tantas modificações propostas para o texto legal, passadas quase duas décadas desde a promulgação da LDB, pouco avançamos para resolver algumas das questões por ela apontadas, a exemplo da desqualificação profissional, das formações fragmentadas e descoladas da educação básica, inclusive o lócus da formação do especialista ainda por ser definido, uma vez que não se encontra devidamente identificado nos cursos de graduação, tampouco na pós-graduação lato e stricto sensu.

Poderia, por exemplo, ser o espaço do mestrado profissional, gratuito e oferecido com edital aberto para toda a comunidade, uma solução para a formação dos especialistas? A respeito da necessária relação entre a formação inicial e o campo de atuação profissional dos egressos dos cursos de licenciatura, que atuarão em sua maioria na educação básica, Borges (2010) já demonstrou ser ponto central a necessidade de o currículo que forma docentes ter intensa ligação com o currículo da escola básica.

Em um estudo sobre a história das políticas de formação docente Borges et. al. (20 I I) reafirmam que o Brasil viveu, na última década, muitas reformas educacionais, mas que a política de formação ainda padece de uma verdadeira revolução. Isso será possível se analisarmos o cenário político sob uma moldura mais ampla, caso contrário, segundo o referido autor (201 I, p. 94), não perceberemos que "[...] as políticas e as práticas do sistema educacional brasileiro encontram-se orientadas pelos valores do neoliberalismo e, por isso, apresentam contradições". Situação confirmada por Saviani (2006, p. I0), ao considerar "[...] a precariedade das políticas formativas, cujas sucessivas mudanças não lograram estabelecer um padrão minimamente consistente de preparação docente para fazer face aos problemas enfrentados pela educação escolar em nosso país".

Importante análise crítica do que se tem produzido no Brasil na esteira das repercussões do texto da lei geral da educação nas políticas públicas educacionais encontra-se na obra referencial de Davies (20 I0). Na retrospectiva histórica dessa temática educacional o autor apresenta os destaques nos textos das nossas sete constituições federais, do Brasil colônia aos anos de reabertura política do país que culminaram em 1988.

Depreendemos dessa obra a informação de que a educação já estava presente na primeira constituição federal do Brasil datada de 1824, em que o analfabetismo já era citado como um problema educacional, cujos sujeitos encontravam-se excluídos da infante cidadania que na época nascia regulada pelo Estado. Na mesma direção, o trabalho do autor nos autoriza ressaltar que as diretrizes da educação nacional figuram desde a Carta Constitucional de 1934, o que é recorrente nos instrumentos normativos que se desdobraram da LDB em vigor, muitas vezes apresentadas como novidade e contraditoriamente como um termo significativo e pouco explorado, o que talvez justifique a profusão e a confusão de sentidos nas orientações que se sobrepõem, desnecessariamente. 
O nosso entendimento é que as diretrizes por si só bastariam para orientar a materialização das políticas emanadas dos textos legais, com o aprofundamento ainda não suficientemente realizado dos seus sentidos teóricos e práticos. $\bigcirc$ que o Brasil precisa na verdade não é de mais legislação educacional, mas de condições de apropriação semântica do campo pelos seus agentes públicos e fazedores de leis, mediadas pelas disponibilidades de recursos de toda ordem. Nisso reside um grande desafio para os educadores e para os intelectuais de esquerda, a construção e a proliferação desta pauta sob a perspectiva crítica, um movimento hercúleo contra-hegemônico.

Um bom exercício dessa prática poderia ter como ponto de partida o trabalho referencial de Bachelard quando nos apresenta a necessidade de apropriação devida das sínteses científicas pelo epistemólogo, que, de alguma forma, pode ser compreendido como o cientista ou produtor de conhecimentos especializados dentro de um campo.

O epistemólogo deve, pois, captar os conceitos científicos em sínteses psicológicas efetivas, isto é, em sínteses psicológicas progressivas, estabelecendo a respeito de cada noção, uma escala de conceitos, mostrando como um conceito deu origem a outro, como está relacionada a outro. Terá, então, alguma probabilidade de avaliar a eficácia epistemológica. (BACHELARD, 1996, pp. |5-16).

Entre esses conceitos que nos são caros no âmbito da temática em tela, destacamos o entendimento ainda incipiente da relevância do real significado do que se denominam diretrizes nacionais de educação e de formação.

\section{O CENÁRIO QUE SE APONTA}

Impossível negar o valor e a importância de uma lei geral do ensino, todavia é preciso considerar que as leis são o ponto de partida de uma política e que a sua materialização requer consenso, reconhecimento público da sua necessidade e credibilidade nas instituições formadoras para torná-la efetiva. Não se pode desconsiderar que o destino final de uma lei da educação leva à modificação dos planos de vida das pessoas e dos planos formativos das instituições.

Apesar de vinte anos passados da LDB, questões candentes da educação ainda não foram equacionadas. Daí a nossa proposição inicial em apontar avanços e recuos no desfecho legal, decorridas duas décadas. A história já demonstrou o insucesso da sobreposição de normativas educacionais, que não respeitaram ainda o ciclo de operacionalização e avaliação de tudo que se criou a partir da Constituição Federal de 1988, inclusive em perspectiva crítica.

Precisamos aprender a absorver o que produzimos intelectualmente e a apropriar em profundidade os conhecimentos do nosso campo para difundi-los e defendê-los, de forma assertiva e 
vigilante. Neste intento, podemos aqui retomar a máxima de Bachelard (1996) quando nos adverte sobre os cuidados em torno da epistemologia.

Dada essa apropriação e aprofundamento, indispensáveis, os sujeitos implicados na educação não podem ficar marginalizados. Eles antecedem a feitura da lei e precisam se ver nela representados.

\section{REFERÊNCIAS}

ADORNO, Theodor W. Educação e emancipação. Rio de Janeiro: Paz e Terra, 2006.

BACHELARD, Gaston. A formação do espírito científico: contribuição para uma psicanálise do conhecimento. Rio de Janeiro: Contraponto, 1996.BRASIL. Presidência da República. Medida Provisória No 746 de 22 de setembro de 2016.

BRASIL. Resolução CNE/CP n 2/20 I 5. Diretrizes Curriculares Nacionais para a Formação Inicial e Continuada dos Profissionais do Magistério da Educação Básica.

BRZEZNSKI, Iria (Org.). LDB dez anos depois: reinterpretação sob diversos olhares. São Paulo: Cortez Editora, 2008.

BORGES, M. C.; AQUINO, O. F.; PUENTES, R. V. Formação de professores no Brasil: história, políticas e perspectivas. Revista HISTEDBR On-line, Campinas, n. 42, p. 94- I I2, jun. 201 I.

BORGES, Lívia Freitas Fonseca. Um currículo para a formação de professores. In: VEIGA, I. P. A.; SILVA, E. F. (Orgs.). A escola mudou. Que mude a formação de professores! Campinas, São Paulo: Papirus, 2010.

CAMBI, Franco. História da pedagogia. São Paulo: Fundação Editora da Unesp, 1999.

CARNEIRO, Waldeck; ARAÚJO, Flávia; PAIVA, Fernando; NEPTUNE, Romã. Institutos Superiores de Educação no Brasil: análise de uma política outorgada pela LDBEN 9394/96. IV Colóquio Internacional de Educação e Contemporaneidade, 2010, São Cristóvão - SE. Educação e Contemporaneidade. São Cristóvão: UFS, 2010, pp. I-14.

CARVALHO, Djalma Pacheco de. A Nova Lei de Diretrizes e Bases e a Formação de Professores para a Educação Básica. Revista Ciênc. educ. (Bauru), vol.5, no.2, 1998.

DAVIES, Nicholas. Legislação educacional federal básica. São Paulo: Cortez, 2010.

FERRETTI, Celso João. Uma nova proposta de orientação profissional. São Paulo: Cortez, 1997.

FREITAS, Luís Carlos de. Responsabilização, meritocracia e privatização: conseguiremos escapar ao neotecnicismo. Trabalho apresentado no III Seminário de Educação Brasileira, Cedes-Unicamp, v. 28, 2011 .

FRIGOTTO, Gaudêncio. "Escola sem partido": imposição da mordaça aos educadores.20 16. Disponível em: http://cpers.com.br/escola-sem-partido-imposicao-da-mordaca-aos-educadores/. Acesso em: II/07/2016. 
GATTI, Bernadete Angelina; BARRETTO, E. S. de S. Professores do Brasil: impasses e desafios. Brasília: Unesco, 2009.

GATTI, Bernadete Angelina; BARETO, Elba Siqueira de Sá; ANDRÉ, Marli Eliza Dalmazo Afonso de; ALMEIDA, Patrícia Cristina Albieri de. Professores do Brasil: novos cenários de formação / Elba. Brasilia: UNESCO, 2019.

HOBSBAWM, Eric. A Era das Revoluções - 1789- | 848. Rio de Janeiro: Paz e Terra, 1996.

IMBERNÓN, Francisco. Formação docente e profissional: forma-se para a mudança e a incerteza. São Paulo: Cortez, 2005.

LIBÂNEO, José Carlos; PIMENTA, Selma Garrido. Formação dos profissionais da educação: visão crítica e perspectivas de mudança. In: PIMENTA, Selma Garrido (Org.). Pedagogia e pedagogos: caminhos e perspectivas. São Paulo: Cortez, 20II .

LIBÂBNEO, José Carlos. Adeus professor, adeus professora? novas exigências educacionais e profissão docente. São Paulo: Cortez, 2010.

LIBÂNEO, José Carlos. Que destino os pedagogos darão à pedagogia? In: PIMENTA, Selma Garrido (Coord.). Pedagogia, ciência da educação? São Paulo: Cortez, 2006.

MACEDO, Elizabeth. Base Nacional Curricular Comum: novas formas de sociabilidade produzindo sentidos para a educação. Revista e-Curriculum, São Paulo, v. I2, n. 03 p. 1530 - 1555 out./dez. 20 I 4.

MACHADO, Juliana Lacerda; PAIXÃO, Divaneide Lira Lima. A educação superior e as políticas de formação para professores da educação básica. In: GUIMARÃES-IOSIF, Ranilce; ZARDO, Sinara Pollom; SANTOS, Aline Veiga (Orgs.). Educação Superior: conjunturas, políticas e perspectivas. Brasília: Liber Livro, 2015.

MALANCHEN, Julia. Cultura, Conhecimento e Currículo: contribuições da pedagogia histórico-crítica. Campinas, SP: Autores Associados, 2016.

MELO, Maria Teresa Leitão de. Programas Oficiais para a Formação dos Professores da Educação Básica. Revista Educação \& Sociedade, ano XX, n 68, Dezembro/99.

MELLO, Guiomar Namo de. Formação Inicial de Professores para a Educação Básica: uma (re)visão radical. Revista Em Perspectiva. I 4 (I) São Paulo, 2000.

NAGLE, Jorge. Educação e Sociedade na Primeira República. Rio de Janeiro: DP\&A, 2001 .

NÓVOA, António. O passado e o presente dos professores. In: NÓVOA, António (Org.). Profissão professor. Porto: Porto Editora, 1999.

PEREIRA, Julio Emílio Diniz. Formação de professores da Educação Básica no Brasil no limiar dos 20 anos da LDBEN. Notandum 42 set-dez 2016 - CEMOrOC - Feusp / IJI-Univ. do Porto, 2016.

ROCHA, Maria Izabel. Otimismo pedagógico. In: FIDALGO; Fernando; MACHADO, Lucília. Dicionário da educação profissional. Belo Horizonte, Ed. UFMG, 2000. 
SANTOS, Jailson Alves dos. A trajetória da Educação Profissional. In: LOPES, Eliane Marta Teixeira; FILHO, Luciano Mendes Faria; VEIGA, Cynthia Greive. 500 Anos de Educação no Brasil. Belo Horizonte: Autêntica, 2003.

SAVIANI, Dermeval. A nova lei da educação: trajetória, limites e perspectivas. Campinas, SP: Autores Associados, 2004.

SAVIANI, Dermeval. Pedagogia e formação de professores no Brasil: vicissitudes dos dois últimos séculos", apresentado na sessão de Comunicação Coordenada Permanências e mudanças na educação brasileira - séculos XIX e XX, no IV Congresso Brasileiro de História da Educação, realizado em Goiânia (GO) de 5 a 8 de novembro de 2006.

SAVIANI, Dermeval. A pedagogia no Brasil: história e teoria. Campinas: Autores Associados, 2012.

SAVIANI, Dermeval. História do Tempo e Tempo da História: estudos de historiografia e história da educação. Campinas, SP: Autores Associados, 2015.

SILVA, Francisco Thiago. Currículo Festivo e Educação das Relações Raciais. Rio Grande: Pluscom Editora, 2015.

SILVA, Tomaz Tadeu da. Apresentação. In: PUCCl (org.). Teoria Crítica e Educação: a questão da formação cultural na Escola de Frankfurt. Petrópolis, RJ: Vozes; São Carlos, SP: EDUFSCAR, 2007. 